\title{
Does monogeny enable gall midges (Diptera: Cecidomyiidae) to regulate their sex ratio?
}

\author{
Seyed Mohammad TABADKANI, Ahmad ASHOURI and Farhad FARHOUDI
}

Department of Plant Protection, College of Horticulture and Plant protection, Faculty of Agriculture and The Natural Resources, University of Tehran, PO Box 4111, Karaj, Iran; e-mail: tabadkani@ut.ac.ir

Key words. Diptera, Cecidomyiidae, Aphidoletes aphidimyza, arrhenogenic, monogeny, sex ratio regulation, thelygenic

\begin{abstract}
Monogeny, the production of unisexual broods by individual females, is widely recorded in gall midges (Diptera: Cecidomyiidae). Theoretical models propose that the adjustment of offspring sex ratio by females may pre-dispose the evolution of monogeny in gall midges however empirical studies in this field are superficial. Expressed more simply, monogeny may enable individual female gall midges to decrease or increase the number of male and female progeny they produce in response to changes in environmental conditions. Host quality/size is repeatedly reported to influence sexual investment in insects in terms of sex ratio adjustment. In this paper, we examined the sex ratio of the offspring of the monogenous predatory gall midge Aphidoletes aphidimyza attacking low and high abundances of the cotton aphid, Aphis gossypii. Two consecutive generations of female gall midges were presented with either a low or high abundance of aphids in each generation and the sex ratio of their progenies determined. There was no difference between the sex ratio of the progenies that developed on the high or low abundance of $A$. gossypii in the two generations. Apparently, the females did not regulate the number of female and male progenies, or adjust the numbers of male or female's eggs they produced in response to the changes in the abundance of prey. Results of this study do not support the theory of sex ratio regulation proposed for monogenous gall midges. It is likely that the skewed sex ratio in most species of monogenous gall midges is a consequence of differential mortality of male and female progenies under harsh conditions. The finding that male and female larvae did not differ in the number of aphids they require to complete their development supports this claim.
\end{abstract}

\section{INTRODUCTION}

Gall midges (Diptera: Cecidomyiidae) belong to one of the largest groups of flies with several species of economic importance in agricultural and forest ecosystems (Barnes, 1946; Gagne, 1994). An unusual reproductive characteristic of some species of gall midges is that of monogeny in which, all offspring of an individual female are either exclusively male or exclusively female (Harris et al., 2003). Monogeny in gall midges is a consequence of their unique sex determination system (Stuart \& Hatchett, 1991), in which a single maternal-effect autosomal gene (chromosome maintenance gene, $\mathrm{Cm}$ ) prevents the elimination of the paternally derived $\mathrm{X}$ chromosome during embryogenesis, so that all of the offspring of $\mathrm{Cm}$-bearing mothers have a female-determining karyotype. The absence of $\mathrm{Cm}$ has the opposite effect; all of the offspring of $\mathrm{Cm}$-lacking females have a male-determining karyotype (Stuart \& Hatchett, 1991; Benatti et al., 2010).

For many animal species, it is generally accepted that there are equal or almost equal numbers of both sexes in natural populations (Omoloye, 2006) and Fisher (1930) and Hamilton (1967) clearly account for why the sex ratio of most animal species tends to be $1: 1$ (Edwards, 2000). However, differential sex allocation is recorded in several taxa (for examples see Hjernquist et al., 2009) and in some cases these are under the control of the parents. Manipulation of the sex ratio of their offspring enables animals to quickly respond to changes in environmental conditions such as an abundance of food, and so, increase their overall fitness (Charnov, 1982). In insects, a large number of empirical studies, mainly on haplodiploid Hymenoptera, have shown that parents are able to adjust the sex ratio of their progenies in response to environmental conditions (Charnov, 1982; Werren, 1984; King, 1993; Morrill et al., 2000; Ode \& Heinz, 2002; Kuijper \& Pen, 2010; Kishani Farahani et al., 2012). In diploid insects, in which both males and females develop from fertilized eggs, adjustment by parents of the sex ratio of their offspring seems unlikely (Bull, 1983; Dorchin \& Freidberg, 2004).

In terms of the effect of the segregation of $\mathrm{Cm}$ during embryogenesis in gall midges (see Benatti et al., 2010), theory predicts a constantly equal number of femaleproducing and male-producing females within populations, so that the overall population sex ratio is $1: 1$ (empirical data include Sell, 1976; Baxendale \& Teetes, 1981; Stuart \& Hatchett, 1991; Dorchin \& Freidberg, 2004). However, there are records of some strictly monogenous populations with a skewed sex ratio, mainly toward females (e.g. Matuszewski, 1982; McClay, 1996; Havelka \& Zemek, 1999; Rajamani et al., 2004; Dorchin et al., 2007; Ogah et al., 2010), which has raised the question of whether gall midges are able to manipulate the sex ratio of their offspring in response to environmental conditions (Barnes, 1931; Werren et al., 2002; Harris et al., 2003)? This ability may appear in two potential ways. First, if the female-producing females and maleproducing females can optionally lay their female and male eggs on high or low quality hosts, respectively, as in Hymenoptera. Here, the males may suffer more mortality 
than the females, due to food shortage or low quality food, however, the ability of male gall midges to mate with several females (van Lenteren \& Schettino, 2003) ensures the reproductive success of all females in a population. Second, monogeny can contribute to sex ratio regulation if thelygenic and arrhenogenic females are able to selectively raise and lower the numbers of their female and male eggs in response to changes in environmental conditions.

In this study, we evaluated the variation in the sex ratio of the predatory gall midge, Aphidoletes aphidimyza Rondani, in response to different abundances of its aphid prey, Aphis gossypii Glover (Hemiptera: Aphididae). A. aphidimyza is a monogenous species (Sell, 1976) and is commercially reared by several companies for the biological control of aphids. The larva of A. aphidimyza is a general predator of over 60 species of aphids. Where aphid populations are high, the larvae kill many more aphids than they can consume, although, less than 10 aphids seem to be enough for full development of the larvae (personal observations). Our preliminary experiments revealed that number of eggs laid by individual females of $A$. aphidimyza ranged from 8 to 122 eggs. This great variation prevented us from using individual females in sex ratio experiments. Additionally, adult $A$. aphidimyza are very delicate and frequently die or fail to reproduce during experiments (in an experiment, only 3 of 16 gall midges laid eggs when individually caged in the laboratory). So, in this study a small population (12 females) was used instead of individual females.

\section{MATERIAL AND METHODS}

\section{Plants and insects}

In order to rear A. gossypii, cucumber seeds (Cucumis sativus) were planted in plastic pots (height $20 \mathrm{~cm}$, diameter $16 \mathrm{~cm}$ ) containing a mixture of peat and soil. Cucumber leaves infested with $A$. gossypii were obtained from commercial greenhouses in the Hashtgerd region (Karaj, Iran) and placed on cucumber plants approximately $15 \mathrm{~cm}$ in size in a research greenhouse, University of Tehran. Bottles containing A. aphidimyza were obtained from a commercial supplier (Koppert Biological Systems, Berkel en Rodenrijs, The Netherlands). The stock colony of $A$. aphidimyza was kept in cages $(1 \mathrm{~m} \times 1 \mathrm{~m} \times 90 \mathrm{~cm})$ with four net walls, wooden bottom and glass ceiling. After adult emergence, some cucumber plants infested with A. gossypii were placed in the cages and the mated females started ovipositing immediately. The cages were kept in a small greenhouse at a temperature of $24 \pm 3{ }^{\circ} \mathrm{C}, 65-75 \%$ relative humidity and a photoperiod of L16 : D8.

The first experiment in this study was carried out using the pea aphid, Acyrthosiphon pisum (Harris) as the prey because of its large body size and ease of counting. Pea aphids and fresh leaves of their host, Vicia fabae (Fabaceae), used in this experiment were obtained from the integrated pest management (IPM) laboratory, University of Tehran.

\section{Assessment of the sex ratio in commercially reared $A$. aphidimyza}

Based on our observations, male A. aphidimyza emerge up to one day earlier than females and their post-mating mortality starts the following day. Therefore, on the second day after emergence of all the adult gall midges from the commercial package and before any died 250 individuals were captured at random and their sex determined based on the structure of their antennae. The males have long hairy antennae, while those of females are shorter and lack long hairs. The sex ratio of commercially reared gall midges was determined by dividing the number of males recorded by the total number individuals (250) in the sample.

\section{Comparison of predation capacity of male and female larvae}

The bias in the sex ratio in favour of females in ideal conditions, especially in Hymenoptera, is understandable in terms of the fact that females usually need more food and make a greater physiological investment in each offspring than males (Thornhill, 1976). In polygynous insects, if conditions are suitable, production of more females will lead to increased overall fitness because each male can fertilize more than one female, which can result in a higher rate of population increase. In all of the species of gall midge studied, females are monandrous and males are polygynous (Harris \& Foster, 1999; van Lenteren \& Schettino, 2003). So, if female larvae consume more food than males in gall midges, the sex ratio is expected to be a function of food availability, i.e. a female biased sex ratio is expected to occur when food resources are sufficient. Otherwise, differential oviposition will not necessarily lead to increased overall fitness. To compare the numbers of aphids that are consumed by male and female larvae, fresh leaves of broad bean, V. fabae were placed in Petri-dishes $(9 \mathrm{~cm}$ diameter $)$ containing agar gel. In each Petri-dish, 20 second instar nymphs of $A$. pisum were released on to the surface of the leaf and allowed to settle down after which a newborn larva of $A$. aphidimyza was also placed on the leaf. The Petri-dishes were kept under controlled laboratory conditions at a temperature of $24 \pm 1{ }^{\circ} \mathrm{C}, 65 \pm 5 \%$ relative humidity and photoperiod of L16 : D8, until the full-grown larvae left the leaves and searched for suitable sites to pupate. At this stage, the larvae were individually transferred using a fine brush into small cylindrical plastic cans (diameter $4 \mathrm{~cm}$, height $4 \mathrm{~cm}$ ) containing humid soil. There was a ventilation hole in the center of the cap of each can, which was covered by fine net. These cans were kept under the same conditions in incubators. The number of aphids killed in each Petri-dish was recorded. After adult emergence, the sex of the individuals was determined. There were 68 replicates of this experiment.

\section{Assessment of the sex ratio of $A$. aphidimyza at different prey abundances}

In this experiment, two abundances of A. gossypii were obtained by releasing 20 and 50 adult wingless aphids (i.e., a low- and high-abundance, respectively) on the surface of cucumber leaves and allowing them to reproduce for $24 \mathrm{~h}$. The pots infested with aphids were each placed under a cylindrical plastic cage (diameter $30 \mathrm{~cm}$ height $40 \mathrm{~cm}$ ). Twelve mated female gall midges were captured at random and released in each cage. As a source of food for the midges a Kleenex tissue was soaked in sugar solution (10\%) and spread out in each cage. The two abundances of aphids were selected based on the number of aphids present at the end of the fifth day, when the second instar midge larvae appear (which includes one day for the adults to lay eggs, three days for the eggs to hatch and one day for the first instar larvae that consume only one or two aphids; personal observation). Assuming an adult aphid produces an average of 6 offspring per day (personal observation), then approximately by the fifth day $1500(6 \times 5 \times 50)$ and 600 $(6 \times 5 \times 20)$ aphids were produced by the initial 50 and 20 adult aphids, respectively. The high abundance of 1500 aphids was sufficient for the full growth of about 150 gall midge larvae and the low abundance of 600 aphids for only 60 gall midge larvae. 
The twelve fertilized gall midges released in each of the cages produced over 100 progeny and the low aphid abundance would have been insufficient for the development of all the larvae.

Of the first generation adults that emerged in each container a maximum of 270 (but often less) were randomly collected and their sex determined. The sex ratio of the offspring was calculated as previously stated. From each container, 12 mated females were placed in a new cage with the same level of aphid abundance as experienced by the previous generation. Again, a maximum number of 230 adult gall midges were collected from these containers and their sex ratio determined. There were 9 replications of this experiment in both generations. Results of this experiment were arcsine transformed and then, independent $t$-tests were used to compare the sex ratios of the offspring that were produced by the gall midges attacking the low and high aphid abundances in the two generations. The data were analyzed using SAS computer software version 9.1 (SAS Institute, Cary, NC, USA).

\section{RESULTS}

\section{Sex ratio of commercially reared $A$. aphidimyza}

The sex ratio of commercially reared gall midges was very slightly male biased (53.2\% males; 133 males vs. 117 females). Previous studies on A. aphidimyza also indicate male biased sex ratio of gall midges obtained from commercial companies (Gilkeson \& Hill, 1986; Heimpel \& Lundgren, 2000). In contrast, a female biased sex ratio is always recorded in natural populations (for example see Havelka \& Zemek, 1999).

\section{Number of aphids consumed by male and female larvae}

There was no significant difference in the numbers of aphids consumed by male and female larvae ( $t$-test: $t=$ 0.873 , $\mathrm{df}=60, P>0.05)$. In this experiment, the larvae consumed 4-16 second instar nymphs of $A$. pisum. The larvae that killed only 7 aphids or less (4 individuals) did not reach maturity. Therefore, the results for these four individuals were not included in analysis. In addition, we failed to find full-grown larvae in two of the replicates. Of the adults that emerged 24 and 38 were female and male, respectively. The male and female larvae consumed an average of 10.65 and 11.12 aphids during their feeding period, respectively. The larvae fed for 3 to 7 days regardless of their sex. This wide range can be attributed to the availability of their host: when aphids are abundant and crowded the larvae complete their feeding earlier.

\section{Variation in the sex ratio of $A$. aphidimyza in response to aphid abundance}

In the first generation, there was no significant difference between the sex ratio of $A$. aphidimyza that developed on the low and high aphid abundances ( $t$-test: $t=$ 1.93 , $\mathrm{df}=16, P>0.05)$. In this generation, the sex ratio of the adult gall midges ranged from $48.4 \%$ to $58.2 \%$ and from $48.3 \%$ to $57.4 \%$ males on the low and high aphid abundances, respectively. In the replicates in which the number of individuals sexed was lower than 270 , we calculated the sex ratio based on all the progeny in the cage. Similarly, the sex ratio of progenies in the second generation on the two aphid abundances was not significantly different ( $t$-test: $t=0.48$, df $=16, P>0.05$ ). The sex

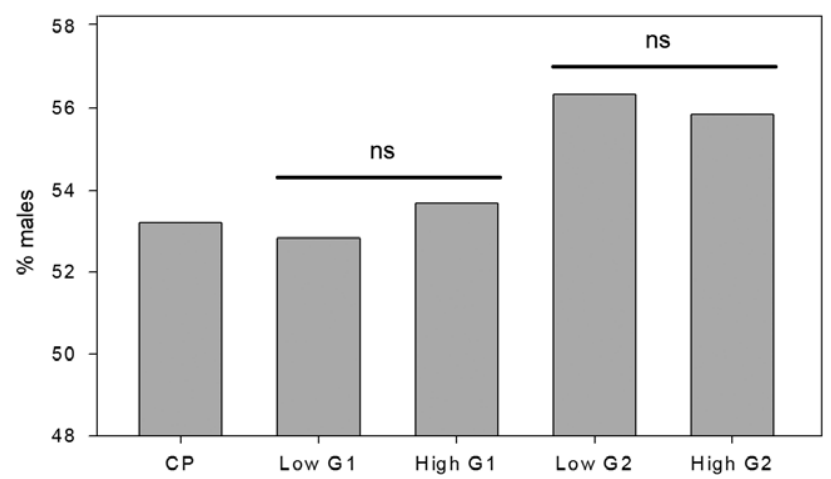

Fig. 1. The percentages of the offspring that are male of Aphidoletes aphidimyza attacking low and high abundances of Aphis gossypii in two consecutive generations (comparisons are of the sex ratios of the progenies developing on the two abundances of prey in each generation, not between those in two generations). $\mathrm{CP}$ - commercial population; $\mathrm{G}$ - generation.

ratios showed bias toward males in each generation regardless of aphid abundance and the differences between them were statistically significant (from 52.85\% to $56.25 \%$ ( $t$-test: $t=6.06$, df $=16, P<0.05$ ) and from $53.74 \%$ to $56 \%$ ( $t$-test: $t=4.43$, df $=16, P<0.05)$ in low and high aphid abundances, respectively, see Fig. 1).

\section{DISCUSSION}

Although, the occurrence of female biased sex ratios are repeatedly reported for various species of gall midges (Baxendale \& Teetes, 1981; Matuszewski, 1982; McClay, 1996; Dorchin \& Freidberg, 2004; Rajamani et al., 2004; Shahu et al., 2004; Smith et al., 2004; Ogah et al., 2010), studies on A. aphidimyza indicate that in this species they are slightly male biased in both laboratory and commercial populations (Gilkeson \& Hill, 1986; Heimpel \& Lundgren, 2000; current study, see Fig. 1). Apparently, the female biased sex ratio in most species of monogenous gall midges is, at least in part, associated with differential pre- and post adult mortality of male and female progenies under harsh conditions (Dorchin \& Freidberg, 2004; Smith et al., 2004; Dorchin et al., 2007). For example, the sex ratio of the wheat midge Sitodiplosis mosellana is biased toward females by $6-11 \%$ as a result of differential mortality during diapause (Smith et al., 2004). We observed that the differences in the lifespan of the sexes of $A$. aphidimyza can result in remarkably female biased sex ratios ( $57 \%$ females) in natural populations.

The numbers of aphids consumed by male and female larvae did not different in our experiment. From these results, we conclude that unlike in Hymenoptera the sex ratio in A. aphidimyza is not dependent on the abundance of its prey. The sex ratios of the offspring of $A$. aphidimyza attacking low and high abundances of prey in both the first and second generations did not differ. These findings do not support the theory that monogeny enables gall midges to regulate their sex ratio. Studies on the gall midge Izeniola obesula, Dorchin \& Freidberg (2004) indicate that the sex ratio of adults emerging from galls of this species varies throughout a year and is as low as $20.5 \%$ male in spring (April, May, June and August) 
rising to a peak of $50 \%$ male in winter (January). In addition, the productivity of galls varied significantly at different times of the year, with the smallest number of midges emerging per gall during spring and summer (April, May, June and August) and the largest number during winter (January) (Dorchin \& Freidberg, 2004). Integrating these results, we conclude that this species also cannot regulate its sex ratio in relation to environmental conditions, because when environmental conditions are unfavourable and, the mortality of the progeny is high, the sex ratio of progeny is biased toward females, whereas during winter and early spring when the environmental conditions, such as host quality and temperature, are suitable and the percentage mortality of the midges is low, a population sex ratio of $1: 1$ is recorded. This means that male gall midges are more susceptible to environmental conditions or other secondary mortality factors than females (Dorchin \& Freidberg, 2004). Consistent with these results are those reported for the monogenous midge Sciara coprophila (Diptera: Sciaridae) in which the females do not adjust the sex ratio of their offspring in response to environmental factors such as temperature (Smith-Stocking, 1936). The sex ratio of the gall midges studied was significantly biased toward males in two generations regardless of prey abundance. We think that this bias is only a consequence of rearing them under laboratory conditions. A similar bias towards males is reported in commercially reared populations (Heimpel \& Lundgren, 2000) and in wild strains of this species reared in the laboratory (Gilkeson \& Hill, 1986). Although, the cause of this bias when reared under laboratory conditions remains to be resolved, we can ignore it because, firstly it has not been recorded in natural populations (Havelka \& Zemek, 1999) and secondly, the same bias was recorded for progeny of the gall midges attacking both low and high abundances of aphids (see Fig. 1).

According to Charnov's model (1982), which was developed for parasitoids and some other haplodiploid Hymenoptera, in order to maximize fitness parental investment in both male and female offspring should be proportional to host size. Several studies on Hymenoptera have shown a correlation between host size/quality and the sex ratios of progenies (Craig et al., 1992; King, 1993; Morrill et al., 2000; Ode \& Heinz, 2002; Kishani Farahani et al., 2012). However, our results along with those of previous studies (e.g. Dorchin \& Freidberg, 2004) definitely indicate that monogenous gall midges do not regulate their offspring sex ratio in relation to host quality/size unlike other haplodiploid arthropods. This is most likely because female gall midges exclusively produce unisexual broods, the fitness of each individual of which is not associated with the sex ratio of her offspring, so each female maximizes her fitness by exploiting the best possible host size/density for her offspring regardless of the sex of her progenies, resulting in a similar spatial distribution of male and female progenies in the host population. Expressed more simply, an arrhenogenic female gall midge does not produce fewer offspring than her thelygenic sisters when the environmental conditions such as food quality and temperature are suitable. Unlike gall midges, haplodiploid insects produce both male and female offspring, and can increase their fitness by ovipositing fertilized eggs on high quality hosts and unfertilized eggs on low quality hosts. If monogeny has not enabled gall midges to regulate their sex ratio, what is the force driving the evolution of monogeny in gall midges?

ACKNOWLEDGEMENTS. We thank H. Allahyari for providing the pea aphids and broad bean plants needed for this study. We are also grateful to M. Qolizadeh, M. Khansefid and F. Khojasteh for their great help with this research. This work was funded by University of Tehran.

\section{REFERENCES}

BARNES H.F. 1931: The sex ratio at the time of emergence and the occurrence of unisexual families in the gall midges (Diptera: Cecidomyiidae). J. Genet. 14: 225-234.

BARNes H.F. 1946: Gall Midges of Economic Importance. I. Gall Midges of Root and Vegetable Crops. Crosby Lockwood, London, $104 \mathrm{pp}$.

Baxendale F.P. \& Teetes G.L. 1981: Production of unisexual progenies by the sorghum midge, Contarinia sorghicola. Ann. Entomol. Soc. Am. 74: 412-413.

Benatti T.R., Valicente F.H., Aggarwal R., Zhao C., Walling G.J., Chen M.S., Cambron S.E., Schemerhorn B.J. \& Stuart J.J. 2010: A neo-sex chromosome that drives postzygotic sex determination in the Hessian fly (Mayetiola destructor). Genetics 184: 769-777.

Bull J.J. 1983: The Evolution of Sex Chromosomes and Sex Determining Mechanisms. Benjamin and Cummings, Menlo Park, CA, 316 pp.

Charnov E.L. 1982: The Theory of Sex Allocation. Princeton University Press, Princeton, NJ, 355 pp.

Craig T.P., Price P.W. \& Itami J.K. 1992: Facultative sex ratio shifts by a herbivorous insect in response to variation in host plant quality. Oecologia 92: 153-161.

Dorchin N. \& Freidberg A. 2004: Sex ratio in relation to season and host plant quality in a monogenous stem-galling midge (Diptera: Cecidomyiidae). Ecol. Entomol. 29: 677-684.

Dorchin N., Clarkin C.E., Scott E.R., Luongo M.P. \& AbraHAMSON W.G. 2007: Taxonomy, life history, and population sex ratios of North American Dasineura (Diptera: Cecidomyiidae) on goldenrods (Asteraceae). Ann. Entomol. Soc. Am. 100: 539-548.

EDWARDS A.W.F. 2000: The genetical theory of natural selection. Genetics 154: 1419-1426.

FisHeR R.A. 1930: The Genetical Theory of Natural Selection. Clarendon Press, Oxford, 272 pp.

GaGne R.J. 1994: The Gall Midges of the Neotropical Region. Cornell University Press, Ithaca, NY, Xv $+352 \mathrm{pp}$.

Gilkeson L.A. \& Hill S.B. 1986: Genetic selection for and evaluation of nondiapause lines of predatory midge, Aphidoletes aphidimyza (Rondani) (Diptera: Cecidomyiidae). Can. Entomol. 118: 869-879.

Hamilton W.D. 1967: Extraordinary sex ratios. Science 156: 477-488.

Harris M.O. \& Foster S.P. 1999: Gall midges. In Hardie J. \& Minks A.K (eds): Pheromones of Non-Lepidopteran Insects Associated with Agricultural Plants. CAB International, New York, NY, pp. 27-49.

Harris M.O., Stuart J.J., Mohan M., Nair S. \& Lamb R.J. 2003: Grasses and gall midges: plant defense and insect adaptation. Annu. Rev. Entomol. 48: 549-577. 
Havelka J. \& ZemeK R. 1999: Life table parameters and oviposition dynamics of various populations of the predacious gallmidge Aphidoletes aphidimyza. Entomol. Exp. Appl. 91: 481-484.

Heimpel G.E. \& Lundgren J.G. 2000: Sex ratios of commercially reared biological control agents. Biol. Contr. 19: 77-93.

Huernquist M.B., HJernquist K.A.T., Forsman J.T. \& GustafsSONA L. 2009: Sex allocation in response to local resource competition over breeding territories. Behav. Ecol. 20: 335-339.

KING B.H. 1993: Sex ratio manipulation by parasitoid wasps. In Wrench D.L. \& Ebbert M.A (eds): Insect Sex Ratios. Chapman and Hall, New York, pp. 402-417.

Kishani Farahani H., Goldansaz S.H. \& Sabahi Q. 2012: A survey on the over-wintering larval parasitoids of Ectomyelois ceratoniae in three regions in Iran. Crop Prot. 36: 52-57.

KuiJPer B. \& Pen I. 2010: The evolution of haplodiploidy by male-killing endosymbionts: importance of population structure and endosymbiont mutualisms. J. Evol. Biol. 23: 40-52.

Matuszewski B. 1982: Diptera I: Cecidomyiidae. In John B. (ed.): Animal Cytogenetics. Insecta 3. Gebruder Borntraeger, Berlin, pp. 91-137.

MCClay A.S. 1996: Unisexual broods in the gall midge Cystiphora sonchi (Bremi) (Diptera: Cecidomyiidae). Can. Entomol. 128: 775-776.

Morrill W.L., Gavor J.W., Weaver D.K., Kushnak G.D. \& IRISH N.J. 2000: Effect of host plant quality on the sex ratio and fitness of female wheat stem sawflies (Hymenoptera: Cephidae). Environ. Entomol. 29: 195-199.

Ode P.J. \& Heinz K.M. 2002: Host size dependent sex ratio theory and improving mass reared parasitoid sex ratios. Biol. Control 24: 31-41.

Ogah E.O., Odebiyi J.A., Ewete F.K., Omoloye A.A. \& NwILENE F.E. 2010: Biology of the African rice gall midge Orseolia oryzivora (Diptera: Cecidomyiidae) and its incidence on wet-season rice in Nigeria. Int. J. Trop. Insect Sci. 30: $32-39$.

Omoloye A.A. 2006: Sex ratio bias in the F1 adult progeny of African rice gall midge, Orseolia oryzivora H. and G. (Dipt., Cecidomyiidae). J. Appl. Entomol. 130: 349-355.
Rajamani S., Pasalu I.C., Mathur K.C. \& Sain M. 2004: Biology and ecology of rice gall midge. In Bennett J., Bentur J.S., Pasalu I.C. \& Krishnaiah K. (eds): New Approaches to Gall Midge Resistance in Rice. Proceedings of the International Workshop, 22-24 November 1998, Hyderabad, India. International Rice Research Institute and Indian Council of Agricultural Research, Los Baños (Philippines), pp. 7-15.

Sell P. 1976: Monogenie bei Aphidoletes aphidimyza (Rond.) (Diptera: Cecidomyiidae). Z. Angew. Entomol. 82: 58-61.

Shahu S.C., Kar B., Behura S.K., Nair S. \& Mohan M. 2004: Genetic conflict over sex determination in rice gall midge. In Bennett J., Bentur J.S., Pasalu I.C. \& Krishnaiah K. (eds): New Approaches to Gall Midge Resistance in Rice. Proceedings of the International Workshop, 22-24 November 1998, Hyderabad, India. International Rice Research Institute and Indian Council of Agricultural Research, Los Baños (Philippines), pp. 17-22.

Smith M.A.H., Wise I.L. \& Lamb R.G. 2004: Sex ratios of Sitodiplosis mosellana (Diptera: Cecidomyiidae): implications for pest management in wheat (Poaceae). Bull. Entomol. Res. 94: $569-575$.

Smith-Stocking H. 1936: Genetic studies on selective segregation of chromosomes in Sciara coprophila Lintner. Genetics 21: 421-443.

Stuart J.J. \& Hatchett J.H. 1991: Genetics of sex determination in the Hessian fly Mayetiola destructor. J. Hered. 82: 43-52.

THORNHILl R. 1976: Sexual selection and paternal investment in insects. Am. Nat. 110: 153-163.

van Lenteren J.C. \& Schettino M. 2003: Kinky sex and suicidal mating behavior in Aphidoletes aphidimyza. Entomol. Berichten. 63: 143-146.

WERREN J.H. 1984: Brood size and sex ratio regulation in the parasitic wasp Nasonia vitripennis (Walker) (Hymenoptera: Pteromalidae). Neth. J. Zool. 34: 123-143.

Werren J.H., Hatcher M.J. \& Godfray H.C.J. 2002: Maternaloffspring conflict leads to the evolution of dominant zygotic sex determination. Heredity 88: 102-111.

Received February 14, 2012; revised and accepted April 6, 2012 